\title{
Kinetic analysis of the dissolution of natural magnesite in nitric acid
}

\author{
Maryna KYSLYTSYNA ${ }^{1}$, Pavel RASCHMAN ${ }^{2}$, Luboš POPOVIČ $\check{3}^{3}$ and Gabriel SUČIK
}

Authors' affiliations and addresses: ${ }^{1}$ Faculty of Materials, Metallurgy and Recycling, Technical University of Košice, Slovakia,

e-mail: maryna.kyslytsyna@tuke.sk

${ }^{2}$ Faculty of Materials, Metallurgy and Recycling, Technical University of Košice, Slovakia,

e-mail: pavel.raschman@tuke.sk

${ }^{3}$ Faculty of Materials, Metallurgy and Recycling, Technical University of Košice, Slovakia,

e-mail: lubos.popovic@tuke.sk

${ }^{4}$ Faculty of Materials, Metallurgy and Recycling, Technical University of Košice, Slovakia,

e-mail: gabriel.sucik@tuke.sk

*Correspondence:

Maryna Kyslytsyna, Faculty of Materials,

Metallurgy and Recycling, Technical

University of Košice, Slovakia,

tel: +42155602 2560

e-mail: maryna.kyslytsyna@tuke.sk

Funding information:

Agency of the Ministry of Education, Science, Research and Sport of the Slovak Republic for the Structural Funds of EU 26220220131

\section{Acknowledgement:}

This work was supported by the Agency of the Ministry of Education, Science, Research and Sport of the Slovak Republic for the Structural Funds of EU, Operational Programme Research and Development, funded by the European Regional Development Fund (Grant ID: 26220220131, project "Advanced Technologies for a Mining Company of the 21st Century").

How to cite this article:

Kyslytsyna, M., Raschman, P., Popovič, P. and Sučik, G. (2020). Kinetic analysis of the dissolution of natural magnesite in nitric acid. Acta Montanistica Slovaca, Volume 25 (1), 3545

DOI:

https://doi.org/10.46544/AMS.v25i1.4

\begin{abstract}
Leaching kinetics of natural magnesite with nitric acid was investigated, and the results of a detailed critical analysis are presented. The reaction system $\mathrm{MgCO}_{3}-\mathrm{HNO}_{3}-\mathrm{H}_{2} \mathrm{O}$ has been studied with special regard to the production of pure magnesium salts. The generalised non-porous shrinking particle model considering the $\mathrm{n}$-th order liquid-solid reaction was fitted to the measured kinetic data and the values of apparent activation energy, $E_{A}$, and reaction order, $n$, were calculated. Relatively high values of $E_{A}\left(43.7\right.$ and $\left.58.5 \mathrm{~kJ} \mathrm{~mol}^{-1}\right)$ obtained for both "low" $(0.01-0.1 \mathrm{M})$ and "high" (1-6 M) concentrations of $\mathrm{HNO}_{3}$, respectively, lay within the range of values presented by other authors and indicate that the overall process is controlled by the chemical reaction in the whole range of reaction conditions considered (temperature from 70 to $100^{\circ} \mathrm{C}$ and concentration of $\mathrm{HNO}_{3}$ from 0.01 to $6 \mathrm{M}$ ). This hypothesis has been confirmed by the calculated values of $n$, which considerably differ from 1 . Until now, it has been assumed in the literature that $n=1$ and no attention has been paid to the actual mechanism of the intrinsic chemical reaction. In this work, the value of $n=0.22$ was calculated for the solutions with "low" $\mathrm{HNO}_{3}$ concentration, and $n=0.05$ was obtained for the concentrated $\mathrm{HNO}_{3}$ solutions. These values of $n$ are considerably lower than the value of $n=0.5$, predicted by the theory. It is hypothesised that the decrease in $\mathrm{n}$ with increased acid concentration might be related to the formation of $\mathrm{CO}_{2}$ and its transfer from the liquid to the gaseous phase.
\end{abstract}

\section{Keywords}

Leaching, shrinking particle model - verification, reaction order, activation energy, rate-determining step.

(C) 2020 by the authors. Submitted for possible open access publication under the terms and conditions of the Creative Commons Attribution (CC BY) license (http://creativecommons.org/licenses/by/4.0/). 


\section{Introduction}

Although magnesium is found in over 60 minerals, only magnesite and other five industrial minerals (dolomite, carnallite, serpentine, brucite and olivine), alongside seawater and brines, are commercially important natural sources of this element (Roskill 2013; USGS, 2019). Formally known as magnesium carbonate $\left(\mathrm{MgCO}_{3}\right)$, magnesite is found around the world (predominantly in Australia, Austria, Brazil, Canada, China, Greece, India, North Korea, Russia, Serbia, Slovakia, Spain and Turkey (Roskill, 2013, EC, 2015)), and its properties make it an invaluable raw-material in numerous fields.

Traditional products made from magnesite are refractory materials, mainly for producing steel, cement and nonferrous metals. More than $99 \%$ of mined and beneficiated magnesite is heat-treated to obtain magnesia (magnesium oxide, $\mathrm{MgO}$ ) - similarly to the production of quicklime from limestone. There are three grades of magnesia available in the market: fused magnesia (FM), dead burned magnesia (DBM) and caustic calcined magnesia (CCM). While the DBM and FM are consumed in the production of refractory materials, CCM is mostly used in chemical-based applications such as fertilisers and livestock feed, pulp and paper, hydrometallurgy and waste-water treatment (Merchant, 2019; Roskill, 2013). However, the producers of magnesite in Europe, the United States, Russia, and other regions have permanently been forced to develop new products and look for new applications - there are at least three major reasons (IHS Markit, 2017; Merchant, 2019; Roskill, 2013): (a) never-ending effort of the steelmakers and cement producers to reduce the specific consumption of refractories; (b) limited growth of global steel and cement production, which has not been able to compensate the corresponding slackening in demand for refractory materials; and (c) huge China's exports of cheaper refractory grade magnesia during last decade. Thus, over the past three decades, the use of magnesite products has spread to agriculture, chemical, pharmaceutics and construction industries, and environmental protection (Roskill, 2013; Shand, 2006). Unlike FM and DBM, demand is foreseen to increase in many end uses; acquisitions take place in the market, and new capacities are appearing (Merchant, 2019; Roskill, 2013). New perspective applications are CCM, lightweight aluminium-magnesium alloys for structural components of automobiles and machinery, and pure magnesium compounds, especially the hydroxide and salts of various inorganic and organic acids (Merchant, 2019; Roskill, 2013; Shand, 2006).

The present work is related to the chemical processing of magnesite into pure magnesium salts. Though the added cost of chemical processing (as compared to the beneficiation of rich ores by physical methods) restricts its use in general, the relative scarcity of high-quality magnesite deposits means in certain circumstances it can be viable to upgrade magnesite via chemical route. Moreover, in mining and beneficiation of magnesite, individual operations can (and normally do!) produce low-grade magnesite which is in traditional manufacturing actually of no use; such a less-valuable, secondary magnesite raw material can advantageously be used as a feedstock for the chemical processing. Thus, the chemical production of pure magnesium salts seems to be one way how to expand the portfolio of high value-added products, make full use of the extracted magnesite and achieve desired economic effectiveness even with smaller volumes of mined magnesite.

Like a typical hydrometallurgical process (Crundwell 2014; Habashi 2005) and many important processes in inorganic chemical technology (such as the production of alumina (Habashi, 2005), magnesia (Shand, 2006) or titanium dioxide (Bedinger, 2018)), the chemical production of pure magnesium salts from magnesite includes three main stages: (a) leaching of the raw-materials, (b) purification of the leachate, and (c) separation of the valuable substance in the form of a saleable product. The leaching stage requires special interest because it determines the technological demands and thus economic viability of the whole process.

The leaching generally involves a rather complex set of elementary steps represented by the transport phenomena and intrinsic chemical reaction(s). It is well known that (Sohn, 1979): (a) Under certain conditions, some of these elementary steps may become the rate-determining step (RDS) of the overall process; (b) the RDS can change depending upon reaction conditions, and thus rate information obtained under a given set of conditions may not be applicable under another set of conditions; (c) frequently there may not be a single ratecontrolling step because several steps may have more or less equal effects on determining the overall rate. The relative importance of these steps could also change in the course of the reaction. Thus, understanding how the individual reaction steps interact with each other is important in determining not only the RDS under given reaction conditions but also whether more than a single step must be considered in expressing the overall rate (Sohn, 1979).

While certain generalisations can be made for heat and mass transfer, and pore diffusion, the adsorption and chemical reaction(s) are highly specific to the nature of the substances involved (Sohn, 1979). With special regard to the manufacturing of pure magnesium salts from magnesite using chemical methods, a number of papers have recently been published to study the leaching kinetics of magnesite in solutions of inorganic and organic acids (Abali et al., 2006; Bakan et al., 2006; Bayrak et al., 2006; Hoşgün and Kurama, 2012; Köse, 2012; Laçin et al., 2005; Özbek et al., 1999; Raza et al., 2013, 2014, 2015, 2016; Rutto and Enweremadu, 2011). However, only the temperature dependence of the leaching rate was examined, and no attention has been paid to the concentration dependence of the intrinsic kinetics, at all. 
The aim of this work is a detailed kinetic analysis of the nitric acid leaching of magnesite, and the paper breakdown is as follows:

1. Formulation of a suitable simulation model to describe the leaching behaviour of the studied reaction system.

2. Model fitting to the results of kinetic leaching experiments and calculating the apparent reaction order $(n)$ and activation energy $\left(E_{A}\right)$.

3. Determination the RDS of the nitric acid leaching of natural magnesite, based on both $n$ and $E_{A}$.

\section{Theoretical}

Simulation model of the leaching process. Let us consider an agitated tank leaching, where the ground raw magnesite with a known content of magnesium carbonate (designated as the solid substance B) undergoes a chemical reaction in the leach solution with hydrogen cations (designated as the species A), and soluble magnesium salt (for example, nitrate), carbon dioxide and water are formed. The overall process involves three steps in a series, which are as follows:

1. Mass transfer of the hydrogen cations from the bulk leach solution to the surface of magnesite particles.

2. The chemical reaction between the reactants $\mathrm{A}$ and $\mathrm{B}$ at the phase interface, according to Eq. (1),

$$
B(s)+a A(a q .) \rightarrow \text { soluble products }
$$

3. Mass transfer of the dissolved products from the surface of the solid particles into the main body of the lixiviant.

For the kinetic regime of leaching, when chemical reaction controls the overall rate of the process, Raschman et al. (2019) derived a generalised non-porous shrinking particle model (NSPM) which can be written in a shortened form using Eq. (2),

$$
\frac{d x_{B}}{d t}=\frac{\frac{3}{R}}{\rho_{S}} \frac{\rho_{L}^{0}}{c_{A b}^{0}} \frac{\phi}{\sigma} r_{A}^{0} F\left(x_{B}\right)
$$

where:

$x_{B}=$ fraction of species $\mathrm{B}$ reacted (degree of conversion of species B);

$t=$ reaction time;

$R=$ initial radius of magnesite particles (i.e., the radius at $t=0$ );

$\rho_{S}=$ density of magnesite particles;

$\rho_{L}^{0}=$ initial density of the lixiviant (leach solution);

$c_{A b}^{0}=$ initial concentration of hydrogen cations in the lixiviant: strong acids such as the nitric or hydrochloric acid are strong electrolytes and are practically fully ionised in water, $c_{A b}^{0}$ is therefore assumed to be equal to the initial concentration of the acid;

$\phi=$ reduced $\mathrm{A} / \mathrm{B}$ molar ratio, $\phi=n_{A}^{0} /\left(a n_{B}^{0}\right) ;$

$n_{A}^{0}$ and $n_{B}^{0}=$ initial total amount (in moles) of the species A and $\mathrm{B}$, respectively;

$a=$ stoichiometric coefficient for the species A in Eq. (1);

$\sigma=$ liquid-to-solid $(L / S)$ mass ratio, $\sigma=m_{L}^{0} / m_{S}^{0}$;

$m_{L}^{0}$ and $m_{S}^{0}=$ initial mass of the lixiviant and magnesite feed-stock, respectively;

$r_{A}^{0}=$ initial rate of the chemical reaction (1) defined by Eq. (3),

$$
r_{A}^{0}=k \gamma_{A}^{n}\left(c_{A b}^{0}\right)^{n}=k_{0} \exp \left(-\frac{E_{A}}{R_{G} T}\right) \gamma_{A}^{n}\left(c_{A b}^{0}\right)^{n}
$$

$k=$ rate-constant for the reaction (1), $n$-th order in A;

$T=$ temperature;

$\gamma_{A}=$ activity coefficient of the species $\mathrm{A}$ in the leach solution;

$n=$ order of chemical reaction (1) with respect to reagent $\mathrm{A}$;

$k_{0}, E_{A}$ and $R_{G}=$ constants ("frequency factor", apparent activation energy of reaction (1) and gas constant, respectively) in Arrhenius' equation $k=k_{0} \exp \left(-\frac{E_{A}}{R_{G} T}\right)$;

$F\left(x_{B}\right)=$ function of the fraction of species B reacted, $x_{B}$, defined as follows:

$$
F\left(x_{B}\right)=\left(1-\frac{x_{B}}{\phi}\right)^{n}\left(1-x_{B}\right)^{\frac{2}{3}} \text {. }
$$


Unlike the commonly used “simple” NSPM (see, for example, Levenspiel (1999), Sohn (1979) or Wadsworth (1979)), the generalised NSPM assumes $n-$ th order chemical reaction, the influence of the $L / S$ ratio and non-ideal behaviour of the leach solution.

For mathematical simplicity, in a kinetic analysis, it is advantageous to apply a simplified form of the NSPM. The simplified NSPM represents the solution of Eqs. (2) to (4) based on the assumption that $n=n$, $\boldsymbol{\phi} \gg \mathbf{1}$ and $\gamma_{A}=f\left(c_{A b}^{0}\right)-$ it can be written in the form of Eqs. (5) and (6) (Raschman et al. 2019):

$$
\begin{aligned}
& 1-\left(1-x_{B}\right)^{\frac{1}{3}}=\frac{t}{t_{R}} \\
& t_{R}=\frac{a n_{B}^{0} \rho_{S} R}{m_{S}^{0} k_{0} \exp \left(-\frac{E_{A}}{R_{G} T}\right) \gamma_{A}^{n}\left(c_{A b}^{0}\right)^{n}} .
\end{aligned}
$$

where: $t_{R}=$ the time required for the complete conversion of a particle of the original raw material.

Sometimes, for practical purposes, the reaction half-time, $t_{0.5}$ (i.e. the time required under certain reaction conditions to dissolve one half of the amount of the valuable substance B initially present in the raw materials), is used as the characteristic time of the leaching process; in such a case $t_{0.5}=0.2063 t_{R}$ and Eq. (5) can be modified to Eq. (7) (Raschman et al., 2019):

$$
1-\left(1-x_{B}\right)^{\frac{1}{3}}=0.2063 \frac{t}{t_{0.5}}
$$

\section{Material and Methods}

Materials. The bulk natural raw magnesite (RM) from the SMZ Jelšava plant, Slovakia, was used in the leaching experiments. The fraction $+80-125 \mu \mathrm{m}$ was prepared by dry mill-grinding, wet-screening, washing by deionised water and drying. The physico-chemical characteristics of the RM sample are given in Table 1. The sample was analysed by wet chemical methods combined with the ICP analysis. Thermal and X-ray powder diffraction analysis proved a ferroan variety of magnesite (breunnerite) to be the prevailing phase, accompanied by small amounts of dolomite and calcite - the results are summarised in Fig. 1. The specific surface area sA < $0.1 \mathrm{~m} 2 \mathrm{~g}-1$ was determined by the B.E.T. nitrogen adsorption technique. Analytical reagent grade chemicals and

\begin{tabular}{|c|c|c|c|c|c|c|c|c|c|c|c|}
\hline \multirow{2}{*}{$\begin{array}{c}\text { Particle } \\
\text { diameter } \\
{\left[10^{-6} \mathrm{~m}\right]}\end{array}$} & \multirow{2}{*}{$\begin{array}{c}\text { Specific } \\
\text { surface area } \\
{\left[10^{3} \mathrm{~m}^{2} \mathrm{~kg}^{-1}\right]}\end{array}$} & \multicolumn{6}{|c|}{ Chemical elemental analysis [wt.\%] } & \multicolumn{4}{|c|}{ Qualitative X-ray phase analysis 1) } \\
\hline & & $\mathrm{Mg}$ & $\mathrm{Fe}$ & $\mathrm{Ca}$ & $\mathrm{Si}$ & $\mathrm{Al}$ & Cinorg. & $\mathrm{M}(\mathrm{B})$ & $\mathrm{S}$ & $\mathrm{D}$ & $\mathrm{C}$ \\
\hline $80-125$ & $<0.1$ & 25.3 & 2.91 & 2.13 & 0.26 & 0.05 & 13.7 & +++ & - & ++ & + \\
\hline
\end{tabular}
deionised water were used in all experiments.

Table 1. Physico-chemical characteristics of used raw magnesite (RM)

${ }^{1)} \mathrm{M}(\mathrm{B})$ = ferroan magnesite (breunnerite); S = siderite; D = dolomite; $\mathrm{C}=$ calcite. "+" = phase detected; " -" = phase not detected.
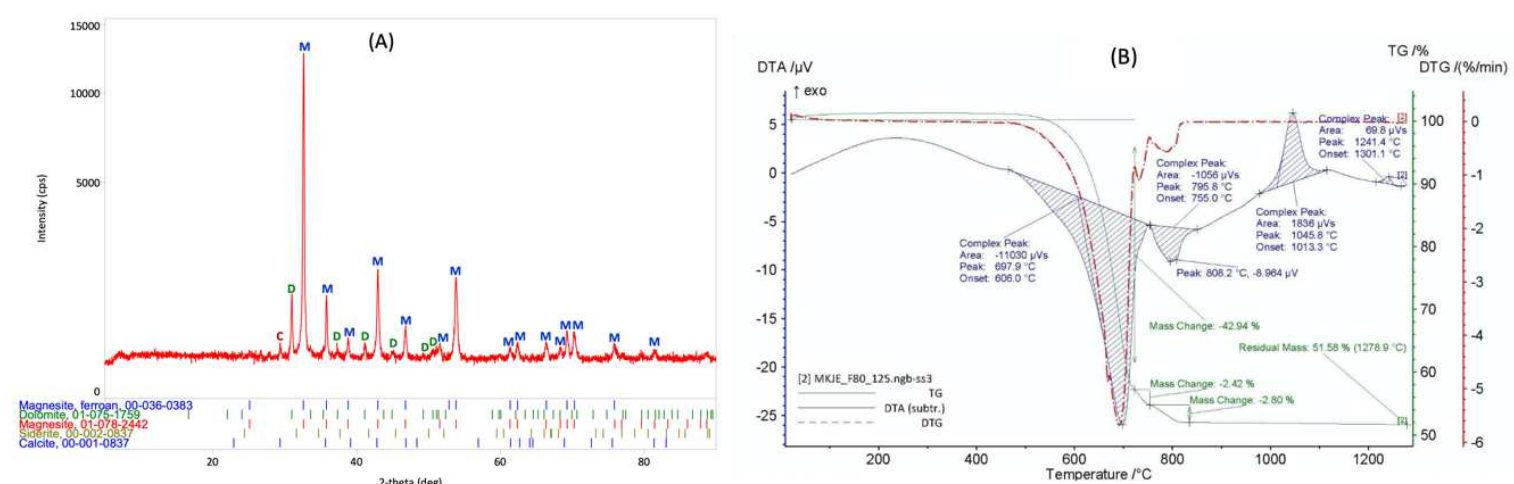

Figure 1. Results of the phase and thermal analysis of natural raw magnesite RM

(A) X-ray diffractogram; $M=$ ferroan magnesite (breunnerite), $D=$ dolomite, $C=$ calcite. $(X$-ray powder diffractometer Rigaku MiniFlex 600, Bragg-Brentano goniometer, CuKa radiation, Ni-filter, working voltage $40 \mathrm{kV}$, current $15 \mathrm{~mA}$.).

(B) Plot of TG, DTG and DTA curves. (Simultaneous thermal analyser Netzsch STA 449 F3 Jupiter, corundum crucible, air atmosphere, temperature rate $10 \mathrm{~K} \mathrm{~min}^{-1}$.) 
Leaching procedure and measuring kinetic data. For the process studied, the overall chemical reaction can be written in the form of equation (8):

$$
\mathrm{MgCO}_{3}(\mathrm{~s})+2 \mathrm{HNO}_{3}(\text { aq. }) \rightarrow \mathrm{Mg}\left(\mathrm{NO}_{3}\right)_{2}(\text { aq. })+\mathrm{CO}_{2}(g)+\mathrm{H}_{2} \mathrm{O}(\mathrm{l})
$$

The leaching behaviour of the RM in nitric acid was tested in a 0.71 isothermal well-mixed glass batch reactor with intermittent withdrawal and analysis of the leachate samples. The reactor was equipped with a hot plate magnetic stirrer, insulating jacket and a reflux condenser. The mixing speed varied from 500 to $700 \mathrm{rpm}$ and had been proved to have no observable effect on the course of leaching, under the reaction conditions considered in the present work. The temperature was maintained to within $2 \mathrm{~K}$. The initial volume of nitric acid was 0.51 in all experiments. In each test, the appropriate L/S ratio was set by the calculated amount of the RM (0.020-3.0 g). The RM sample was added to $\mathrm{HNO}_{3}$ when the desired temperature had been reached in the reactor. The reaction suspension volume has not been affected by evaporation. The $20 \mathrm{ml}$ leachate samples were withdrawn from the reaction mixture at predetermined time intervals, filtered and analysed for the magnesium and calcium by the EDTA and ICP methods. The leaching experiments were carried out under the reaction conditions, which were: temperature from 70 to $100^{\circ} \mathrm{C}$, the concentration of $\mathrm{HNO}_{3}$ from 0.01 to $6 \mathrm{M}$.

\section{Results}

Proposed simulation model. In most work on the leaching of magnesite with concentrated solutions of acids, practically no attention has been paid to the concentration dependence of the intrinsic kinetics. A simple first-order rate expression has been assumed, for mathematical simplicity rather than for valid reasons. In many practical cases, fluid-solid reactions can indeed be approximated as first-order reactions; in general, however, the concentration dependence is much more complex (Sohn, 1979). Crundwell $(2013 ; 2014)$ emphasised the need to derive the value of $n$ on the basis of a suitable mathematical model of the chemical dissolution of the solid substance B and verify it by experiment. Use of the relationship (3) enables to experimentally determine the (apparent) reaction order, $n$, compare it with theory and thus to identify the RDS of the overall leaching process with higher reliability, as compared to the commonly used NSPM.

A preliminary parametric study using the generalised non-porous shrinking particle model of leaching has shown that the values of parameters $n$ and $\phi$ can alter the leaching behaviour qualitatively. In contrast, the activity coefficient of a strong acid just slightly modifies the shape of the kinetic curves but does not change the overall picture. Thus, for simplicity, it has been further assumed that $\gamma_{A} \cong 1$.

During the reaction of magnesite with acids, $\mathrm{CO}_{2}$ is formed and released in a gaseous form from the reaction mixture into the atmosphere. So far, no consideration has been given to the effect of the occurrence of $\mathrm{CO}_{2}$ on the overall leaching rate. The suitability of the proposed simulation model also for description of a reaction systems with the evolving gaseous product has, therefore, to be verified first, by comparing the model prediction with the experiment.

Experimental results. The leaching behaviour of the RM was studied in a large excess of nitric acid. An overview of the leaching tests carried out is given in Table 2. The measured fraction of magnesium dissolved, $x_{B}$, vs. time, $t$, dependencies are illustrated by some typical examples shown in Figure 2. The results of all leaching tests were used to verify the proposed simulation model and to calculate the values of kinetic model parameters.

Table 2. Reaction conditions set in individual leaching tests ${ }^{1)}$

\begin{tabular}{|c|c|c|c|c|c|c|c|c|c|c|c|}
\hline \multirow{3}{*}{$\begin{array}{c}\text { Temperature } \\
{\left[\mathrm{K} /{ }^{\circ} \mathrm{C}\right]}\end{array}$} & \multicolumn{11}{|c|}{ Initial concentration of nitric acid $[\mathrm{M}]$} \\
\hline & \multicolumn{5}{|c|}{ "low" 2) } & \multicolumn{6}{|c|}{ "high" 2) } \\
\hline & 0.01 & 0.02 & 0.04 & 0.06 & 0.1 & 1 & 2 & 3 & 4 & 5 & 6 \\
\hline $343 / 70$ & & & & & & + & & & & + & \\
\hline $353 / 80$ & + & & & & + & & & & & & \\
\hline $358 / 85$ & & & & & & + & & & & + & \\
\hline $363 / 90$ & + & & & & + & & & & & & \\
\hline $373 / 100$ & + & +++ & ++ & ++ & ++ & ++ & ++ & ++ & ++ & ++ & ++ \\
\hline
\end{tabular}

1) Each "+" represents one leaching test carried out ("++..." denotes repeated tests).

2) The initial concentration of HNO3 is declared to be "low" or "high" only with respect to Fig. 3 and further discussion. 
(A)

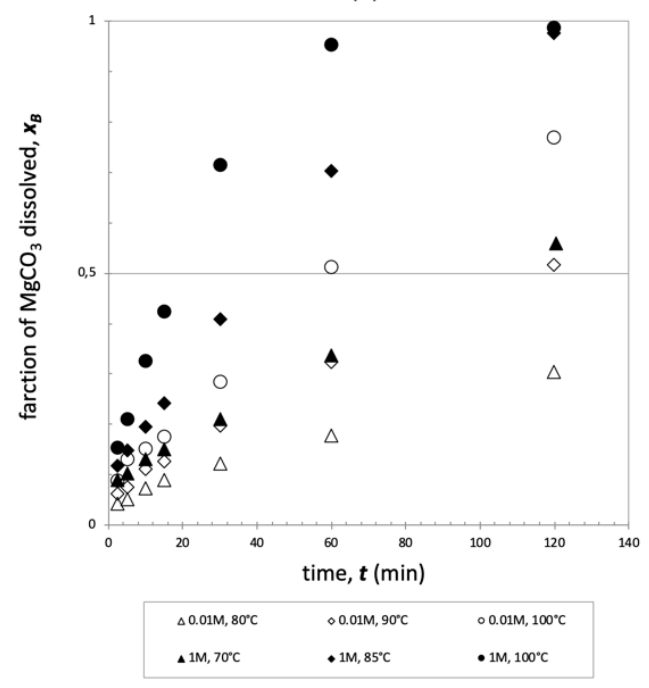

(B)

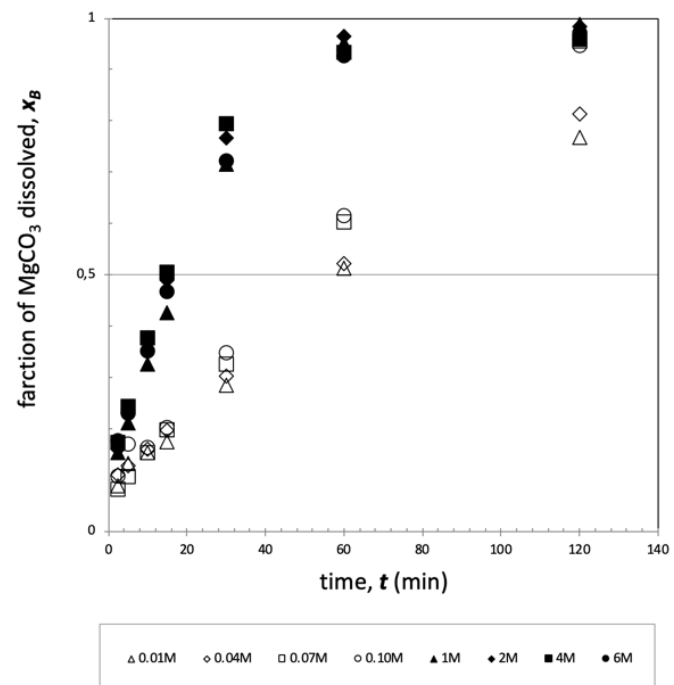

Figure 2. Examples of measured conversion $\left(x_{B}\right)$ vs. time $(t)$ kinetic curves: $(A)$ effect of reaction temperature $\left(c_{H N O_{3}}^{0}=0.01\right.$ and 1 M); $(B)$ effect of nitric acid concentration $\left(T=373 \mathrm{~K} / 100^{\circ} \mathrm{C}\right)$.

\section{Discussion}

Comparison model - experiment. A number of papers have been published to study the leaching kinetics of magnesite in solutions of inorganic and organic acids (Abali et al., 2006; Bakan et al., 2006; Bayrak et al., 2006; Hoşgün and Kurama, 2012; Köse, 2012; Laçin et al., 2005; Özbek et al., 1999; Raza et al., 2013, 2014, 2015, 2016; Rutto and Enweremadu, 2011). A thorough analysis of these studies has revealed that:

1. The leaching rate is very sensitive to temperature - this fact is reflected in high calculated values of the apparent activation energy, $E_{A}\left(42 \mathrm{~kJ} \mathrm{~mol}^{-1}<E_{A}<78 \mathrm{~kJ} \mathrm{~mol}^{-1}\right)$, and, based on these results, the intrinsic chemical reaction has been identified to be the RDS.

2. No attention has been paid to the concentration dependence of the intrinsic kinetics. The shrinking particle model derived for the first-order fluid-solid reaction has exclusively been fitted to the experimental results, despite the fact that the data often had shown large deviations from the first-order reaction behaviour (distinct already by a preliminary visual assessment of the data!). Typical examples are schematically illustrated in Fig. 3: the leaching rate vs. acid concentration $\left(c_{A}\right)$ dependences were first growing at a certain concentration interval $\left\langle c_{A, 1} ; c_{A, 2}\right\rangle$, but further either (a) indicated a weakening effect of the acid concentration in more concentrated solutions (i.e. in solutions with $c_{A}>c_{A, 2}$ ) (Köse, 2012; Raza et al., 2013, 2014) - Fig. 3a; or (b) passed the maximum at $c_{A, M}$ and then even declined for $c_{A}>$ $c_{A, M}$ (Bakan et al., 2006; Bayrak et al., 2006; Laçin et al., 2005) - Fig. 3 b.

(A)

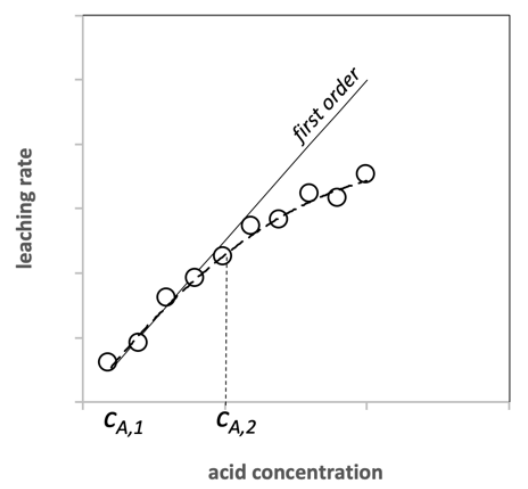

(B)

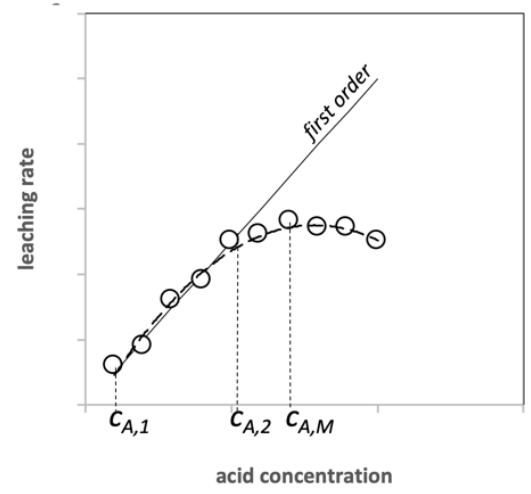

Figure 3. Schematic illustration of the leaching rate vs. acid concentration dependences obtained by some of the previous authors for the acid leaching of natural magnesite - two types of deviations from the first-order model are shown: $(A)$ relative slow-down of the leaching (as compared to the first-order reaction); $(B)$ absolute slow-down of the leaching process in concentrated solutions of acids.

$\underline{\text { Points }}=$ measured data,$\underline{\text { solid line }}=$ the course of leaching assuming the first-order reaction. 
As discussed at the end of the theoretical section, at high L/S ratio when the condition $\phi \gg 1$ (or (1$\left.x_{A}\right) \approx 1$ ) is fulfilled, a simplified NSPM in the form of Eqs. (5) and (6) should fit to the measured dependences $x_{B}$ vs. $t / t_{R}$ and $x_{B}$ vs. $t / t_{0.5}$, respectively. Thus, the nitric acid leaching of the RM was studied in a large excess of the acid when the condition $\phi \gg 1$ was fulfilled. At first, a series of leaching tests characterised by the value of parameter $\phi \geq 10$ (which represents at least the 10 -fold excess of $\mathrm{HNO}_{3}$ if compared to stoichiometry) were carried out; the actual set up values of $\phi$ reached up to 48 (in $6 \mathrm{M} \mathrm{HNO}_{3}$ ). Then, the applicability of Eq. (6) was checked using graphical analysis. To construct a scatter diagram, the half-time of reaction, $t_{0.5}$, has been preferred to $t_{R}$, because it is straightforward to determine $t_{0.5}$ for each run simply by interpolating the measured $x_{B^{-}} t$ data. The scatter diagram shown in Fig. 4 revealed that there is a very good correlation between the simulation model used and experiment (full and open triangles). This fact proved that the simplified NSPM is able to describe the course of leaching in the studied reaction system with acceptable accuracy.

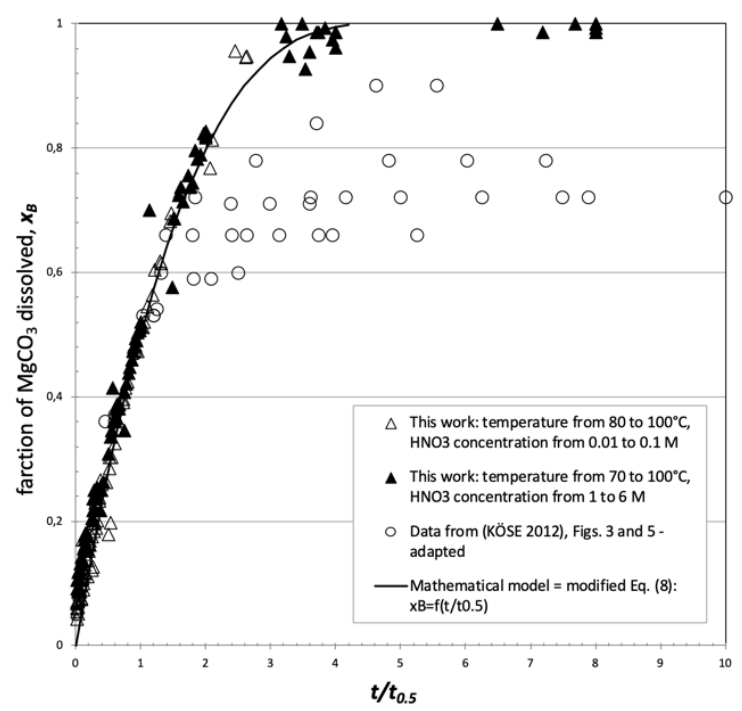

Figure 4. Conversion $\left(x_{B}\right)$ vs. reduced time $\left(t / t_{0.5}\right)$ dependence - comparison of a mathematical model with experiment. $\underline{\text { Points }}=$ measured data, solid line $=$ modified Eq. (7): $x_{B}=1-\left(1-0.2063 t / t_{0.5}\right)^{3}$.

Determining the values of model kinetic parameters. For determining the values of model kinetic parameters, first (assuming for simplicity that $\gamma_{A} \cong 1$ ), Eq. (6) has been modified to express the half-time of reaction, $t_{0.5}$ :

$$
t_{0.5}=0.2063 t_{R}=0.2063 \frac{a n_{B}^{0} \rho_{S} R}{m_{S}^{0} k_{0} \exp \left(-\frac{E_{A}}{R_{G} T}\right)\left(c_{A b}^{0}\right)^{n}} .
$$

Then, the values of $n$ and $E_{A}$ were calculated by linear regression using Eqs. (10) and (11), respectively,

$$
\begin{aligned}
& \ln t_{0.5}=-n \ln c_{A b}^{0}+\text { const } 1, \\
& \ln t_{0.5}=\frac{E_{A}}{R_{G}} \frac{1}{T}+\text { const } 2 .
\end{aligned}
$$

\begin{tabular}{|c|c|c|c|}
\hline & \multicolumn{2}{|c|}{ This work } & \multirow{2}{*}{$\frac{\text { Ref. Köse (2012) }}{\text { Turkey }}$} \\
\hline $\begin{array}{c}\text { Country of the origin of the } \\
\text { magnesite tested }\end{array}$ & Slovakia & Slovakia & \\
\hline$T\left(\mathrm{~K} /{ }^{\circ} \mathrm{C}\right)$ & $353-373(80-100)$ & $343-373(70-100)$ & $303-333(30-60)$ \\
\hline$c_{\mathrm{HNO} 3}^{0}\left(10^{3} \mathrm{~mol} \mathrm{~m}^{-3}\right)$ & 0.01-0.1 ("low”) & 1-6 ("high") & $1-3$ \\
\hline $\mathrm{R}\left(10^{-6} \mathrm{~m}\right)$ & $80-125$ & $80-125$ & $90-150$ \\
\hline $\boldsymbol{E}_{\boldsymbol{A}}\left(10^{3} \mathrm{~J} \mathrm{~mol}^{-1}\right)$ & 43.7 & 58.5 & 3.2 \\
\hline $\boldsymbol{n}(-)$ & 0.22 & 0.05 & - \\
\hline
\end{tabular}

and are summarised in Table 3.

Table 3. Kinetic parameters of the simulation model fitted by experiments 
The values of apparent activation energy obtained in this work, both at low and high concentrations of $\mathrm{HNO}_{3}$ (43.7 a $58.5 \mathrm{~kJ} \mathrm{~mol}^{-1}$, respectively), are in good agreement with the values presented by other authors for the natural magnesite leaching with solutions of inorganic and organic acids $\left(42 \mathrm{~kJ} \mathrm{~mol}^{-1}<E_{A}<78 \mathrm{~kJ}^{\mathrm{mol}}{ }^{-1}\right.$ (Bakan et al., 2006; Bayrak et al., 2006; Hoşgün and Kurama, 2012; Laçin et al., 2005; Raza et al., 2013, 2014, 2015, 2016; Rutto and Enweremadu, 2011)), except a markedly lower value presented by Köse (2012) - see Table 3, for comparison. Köse (2012) investigated the same reaction system (i.e., $\mathrm{MgCO}_{3}-\mathrm{HNO}_{3}-\mathrm{H}_{2} \mathrm{O}$ ); his experimental results were therefore analysed in more detail. Since the values of $\phi$ used in his experiments (from 12 to 20) were high enough and the effect of the $\mathrm{HNO}_{3}: \mathrm{MgCO}_{3}$ ratio may have been excluded, to find an explanation for such a big difference, the original experimental results published by Köse were depicted in a modified form in Figure 4 (open rings), alongside our data (triangles).

A thorough view of all the experimental points in the graph in Figure 4 revealed a considerable difference between the layout of both sets of results. The data points of Köse (a) significantly depart from the model prediction at $x_{B} \geq 0.6$, and (b) indicate that the magnesium dissolution may have been finished by reaching the limit (maximum) value of $x_{B}$ lying between 0.7 and 0.9 .

The dissolution far from equilibrium was studied in both cases, and magnesite was expected to be fully dissolved at the end of the leaching process. The differences observed were therefore attributed either to (a) the presence of a magnesium bearing phase other than magnesite, which did not dissolve in $\mathrm{HNO}_{3}$ at all or exhibited only a limited solubility (this seems unlikely!) or to (b) the errors in chemical analyses and/or calculations. In the sample RM, the total content of mineral phases other than "chemically soluble" carbonates was less than $1 \mathrm{wt}$. $\%$. Hence, the maximum conversions of magnesium carbonate higher than 99 rel. $\%$ may, therefore, have been expected in the present work. This assumption was confirmed by experiment: in the leaching tests where, based on the results of chemical analyses, the carbonates were practically fully dissolved, the experimentally determined undissolved residuals represented less than $2 \mathrm{wt}$ \% of the original RM sample. In the magnesite sample used by Köse, the total content of magnesium and calcium carbonate was even higher, his maximum conversions observed seem therefore to be unrealistically low. Moreover, an inconsistency between the measured data and the mathematical model used to calculate $E_{A}$ is evident from Figure 4, which significantly reduces the reliability of the estimate of $E_{A}$. Thus, with respect to the above facts, the value published by Köse (2012) has been considered to be an outlier.

In the previous research on the leaching of natural magnesite with concentrated solutions of acids, to analyse the overall process, mathematical models having implicitly assumed that $n=1$ were used and the authors paid no further attention to the actual mechanism of the intrinsic chemical reaction (1). However, Crundwell $(2013,2014,2015)$ clearly explained how important physically correct proposal of the mechanism and the related values of kinetic parameters (i.e., apparent activation energy, but especially reaction order) are in finding out the rate-determining step of the overall leaching process. For the far from equilibrium dissolution of $\mathrm{CaCO}_{3}$ in acidic solutions, Crundwell (2015) theoretically derived the value of $n=0.5$ - this theoretical value is twice that calculated in this work for the solutions with "low" $\mathrm{HNO}_{3}$ concentration $(n=0.22)$, and by order of magnitude higher than the value of $n$ obtained for concentrated solutions $(n=0.05)$. For further discussion, due to the lack of relevant data, the experimental results recently published by Artamonova et al. (2017) for the magnesite dissolution kinetics in acidic $(\mathrm{KCl}+\mathrm{HCl})$ solutions at $\mathrm{pH} 1$ to 5 have also been taken into account - an overview of all the above results is shown in Figure 5.

(A)

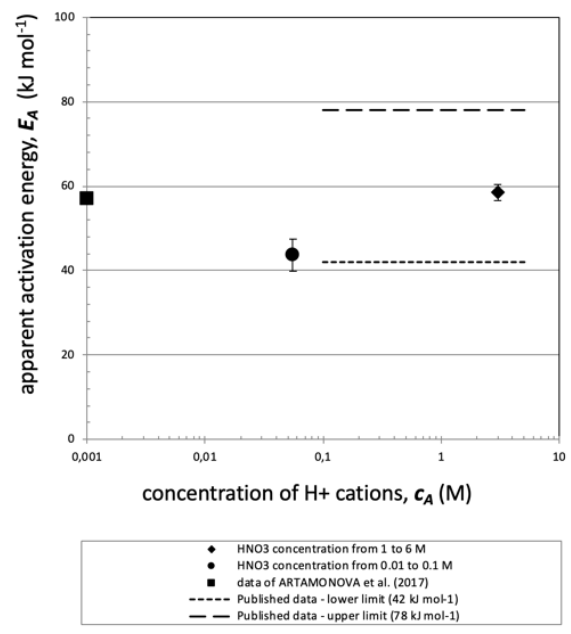

(B)

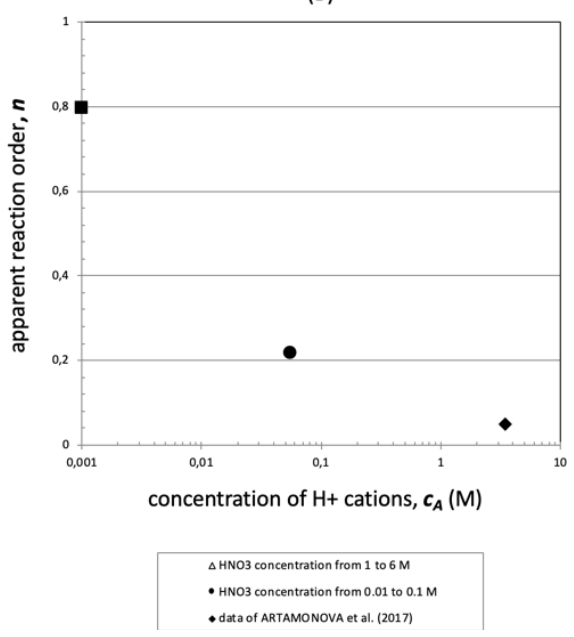

Figure 5. Comparison of the values of kinetic parameters obtained in this work with those found in the literature: (A) apparent activation energy; (B) apparent reaction order in $\mathrm{H}^{+}$ions. 
Jordan et al. (2007) observed a negligible effect of most common organic and inorganic ligands on $\mathrm{MgCO}_{3}$ dissolution in acidic saline solutions, which makes the comparison illustrated in Figs. 5ab feasible. It revealed that:

a) The $E_{A}$ values obtained in this work are lying within the range of the values found by all other previous authors who have studied the leaching of natural magnesite with acid solutions.

b) Critical evaluation of the available values of $n$ indicates that the value of $n$ decreases with increasing acid concentration. This may be related to the formation of $\mathrm{CO}_{2}$ and its transfer from the liquid to the gaseous phase. Since, until now, no consideration has been given to this aspect of the leaching process, and the available data is very limited, the effect of evolved gas should be addressed in more detail in the future.

c) Relatively high calculated values of the activation energy indicate that the overall process of leaching is controlled by the intrinsic chemical reaction (1) in the whole range of temperature and $\mathrm{HNO}_{3}$ concentration studied. This hypothesis has been confirmed by the calculated values of the reaction order, which significantly differ from 1 .

\section{Conclusions}

Kinetics of the leaching of natural magnesite with nitric acid was studied using both mathematical modelling and experiment. The reaction system $\mathrm{MgCO}_{3}-\mathrm{HNO}_{3}-\mathrm{H}_{2} \mathrm{O}$ has been chosen with special regard to the production of pure magnesium salts. The results of a detailed critical analysis are summarised as follows:

1. The generalised non-porous shrinking particle model considering the $n$-th order liquid-solid reaction was fitted to the measured kinetic data and the values of apparent activation energy, $E_{A}$, and reaction order, $n$, were calculated.

2. Relatively high values of $E_{A}\left(43.7\right.$ and $\left.58.5 \mathrm{~kJ} \mathrm{~mol}^{-1}\right)$ obtained in this work for both "low" $(0.01-0.1 \mathrm{M})$ and "high" (1-6 M) concentrations of $\mathrm{HNO}_{3}$, respectively, lay within the range of values presented by other authors and indicate that the overall process of leaching is controlled by the intrinsic chemical reaction (1) in the whole range of reaction conditions considered.

3. This hypothesis has been confirmed by the calculated values of $n$, which (especially in concentrated $\mathrm{HNO}_{3}$ ) considerably differ from 1 . Until now, no attention has been paid to the actual mechanism of the intrinsic chemical reaction. In this work, the value of $n=0.22$ was calculated for the solutions with "low" $\mathrm{HNO}_{3}$ concentration, and $n=0.05$ was obtained for concentrated $\mathrm{HNO}_{3}$ solutions. These results enable a deeper insight not only into the reaction system studied but into the acid leaching of magnesite in general. The calculated values of $n$ seem to be considerably lower than the value predicted by the theory, and it is hypothesised that the decrease in $n$ with increased acid concentration might be related to the formation of $\mathrm{CO}_{2}$ and its transfer from the liquid to the gaseous phase.

\section{Notation}

$\begin{array}{ll}a & \text { stoichiometric coefficient for species } A \text { in Eq. (1) } \\ A & \mathrm{H}+\text { ions } \\ B & \mathrm{MgCO}_{3} \\ c_{A b}^{0} & \text { initial concentration of } \mathrm{H}+\text { ions in bulk lixiviant } \\ E A & \text { apparent activation energy of reaction (1) } \\ F\left(x_{B}\right) & \text { function defined by Eq. (4) } \\ k & \text { rate-constant for reaction (1), } n \text {-th order in } A ; \\ k_{0} & \text { constant ("frequency factor") in Arrhenius' equation; } \\ K & \text { process parameter defined by Eq. (3) } \\ m_{L}^{0} & \text { initial mass of acid leach solution } \\ m_{S}^{0} & \text { initial mass of magnesite } \\ n & \text { apparent reaction order for } \mathrm{H}+\text { ions } \\ n_{A}^{0} & \text { initial total amount (in moles) of species A in lixiviant } \\ n_{B}^{0} & \text { initial total amount (in moles) of } \mathrm{MgCO}_{3} \text { in magnesite } \\ r_{A}^{0} & \text { initial reaction rate defined by Eq. (3); } \\ R & \text { initial radius of magnesite particles } \\ R_{G} & \text { gas constant }=8.314 \mathrm{~J} \text { mol- } 1 \mathrm{~K}-1 \\ t & \text { reaction (leaching) time } \\ t_{0.5} & \text { reaction half-time } \\ t_{R} & \text { time required for complete conversion of magnesite particle } \\ T & \text { temperature in } \mathrm{K} \\ x_{B} & \text { fraction of } \mathrm{MgCO} \text { dissolved }\end{array}$




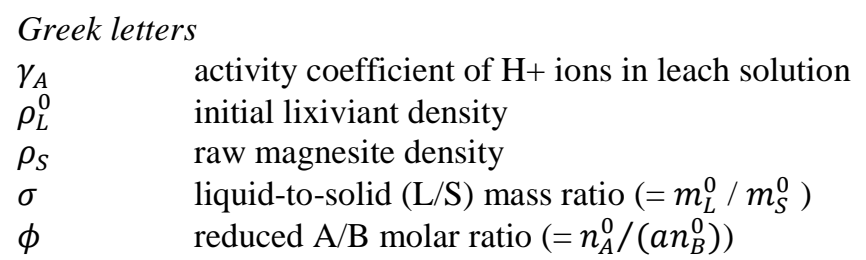

\section{References}

Abali, Y., Çopur, M., Yavuz, M. (2006). Determination of the optimum conditions for the dissolution of magnesite with H2SO4 solutions. Indian Journal of Chemical Technology 13, 391-397.

Artamonova, I.V., Gorichev, I.G., Kramer, S.M. (2017). Comparative analysis of dissolution kinetics of Ca, Mg, $\mathrm{Fe}$, and Mn carbonates. Vestnik of the State University of Nizhni Novgorod (Lobachevsky University) №5 (103), 57-61 (in Russian).

Bakan, F., Laçin, O., Bayrak, B., Saraç, H. (2006). Dissolution kinetics of natural magnesite in lactic acid solutions. Int. J. Miner. Process. 80, 27-34.

Bayrak, B., Laçin, O., Bakan, F. Saraç, H. (2006). Investigation of dissolution kinetics of natural magnesite in gluconic acid solutions. Chemical Engineering Journal 117, 109-115.

Bedinger, G.M. (2018). 2015 Minerals Yearbook -Titanium [Advance Release]. U.S. Geological Survey.

Crundwell, F.K. (2013). The dissolution and leaching of minerals - Mechanisms, myths and misunderstandings. Hydrometallurgy 139, 132-148.

Crundwell, F.K. (2014). The mechanism of dissolution of minerals in acidic and alkaline solutions: Part I - A new theory of non-oxidation dissolution. Hydrometallurgy 149, 252-264.

Crundwell, F.K. (2015). The mechanism of dissolution of minerals in acidic and alkaline solutions: Part IV Equilibrium and near-equilibrium behaviour. Hydrometallurgy 153, 46-57.

European Commission (2015). Critical Raw Materials Profiles, Report on critical raw materials for the EU. European Commission, Ref. Ares(2015)3396873 - 14/08/2015.

Habashi, F. (2005). A short history of hydrometallurgy. Hydrometallurgy 79, 15-22.

Habashi, F. (2007). A generalised kinetic model for hydrometallurgical processes. Chemical Product and Process Modeling 2, Iss. 1, Art. 1.

Hoşgün, H.L., Kurama, H. (2012). Dissolution kinetics of magnesite waste in HCl solution. Ind. Eng. Chem. Res. 51, 1087-1092.

IHS Markit Chemical Expert (2017). Chemical Economics Handbook - Magnesium Oxide and Other Magnesium Chemicals.

Jordan, G., Pokrovsky, O.S., Guichet, X., Schmahl, W.W. (2007). Organic and inorganic ligand effects on magnesite dissolution at $100{ }^{\circ} \mathrm{C}$ and $\mathrm{pH}=5$ to 10 . Chemical Geology $242,484-496$.

Köse, T.E. (2012). Dissolution of magnesium from natural magnesite ore by nitric acid leaching. Journal of Engineering and Architecture Faculty of Eskişehir Osmangazi University XXV (2), 43-55.

Laçin, O., Dönmez, B., Demir, F. (2005). Dissolution kinetics of natural magnesite in acetic acid solutions. Int. J. Miner. Process. 75, 91- 99.

Levenspiel, O. (1999). Chemical Reaction Engineering (3-rd edition). John Wiley \& Sons, New York.

Merchant Research and Consulting Ltd. (2019). Magnesium and Compounds: 2019 World Market Review and Forecast to 2028.

Özbek, H., Abali, Y., Çolak, S., Ceyhun, I., Karagölge, Z. (1999). Dissolution kinetics of magnesite mineral in water saturated by chlorine gas. Hydrometallurgy 51, 173-185.

Raschman, P., Popovič, L', Fedoročková, A., Kyslytsyna, M., Sučik, G. (2019). Non-porous shrinking particle model of leaching at low liquid-to-solid ratio. Hydrometallurgy 190 - in press. https://doi.org/10.1016/j.hydromet.2019.105151.

Raza, N., Zafar, Z.I., Najam-ul-Haq, M. (2013). An analytical model approach for the dissolution kinetics of magnesite ore using ascorbic acid as leaching agent. International Journal of metals 2013, Article ID 352496.

Raza, N., Zafar, Z.I., Najam-ul-Haq, M. (2014). Utilisation of formic acid solutions in leaching reaction kinetics of natural magnesite ores. Hydrometallurgy 149, 183-188.

Raza, N., Zafar, Z.I., Najam-ul-Haq, M., Kumar, R.V. (2015). Leaching of natural magnesite ore in succinic acid solutions. Int. J. Miner. Process. 139, 25-30.

Raza, N., Raza, W., Asif, M. (2016). Reaction kinetics of magnesite ore in dilute ethanoic acid. Russian Journal of Nonferrous Metals 57 (4), 308-315. 
Roskill Information Services Ltd. (2013). Magnesium Compounds and Chemicals: Global Industry Markets and Outlook (12 $2^{\text {th }}$ ed.).

Rutto, H.L., Enweremadu, Ch. (2011). The dissolution study of a South African magnesium-based material from different sources using a pH-stat. Chemical Industry and Chemical Engineering Quarterly 17 (4), 459468.

Shand, M.A. (2006). The Chemistry and Technology of Magnesia. John Wiley \& Sons, Hoboken, New Jersey.

Sohn, H.Y. (1979). Fundamentals of the Kinetics of Heterogeneous Reaction Systems in Extractive Metallurgy. In: Sohn H.Y. and Wadsworth M.E. (Editors): Rate Processes of Extractive Metallurgy. Plenum Press, New York, pp. 1-51.

U. S. Geological Survey (2019). Mineral Commodity Summaries - Magnesium Compounds.

Wadsworth, M.E. (1979). Hydrometallurgical Processes - Principles of Leaching. In: Sohn H.Y. and Wadsworth M.E. (Editors): Rate Processes of Extractive Metallurgy. Plenum Press, New York, pp. 133-186. 